\title{
HOW STUDENTS OF PRIMARY SCHOOL UNDERSTAND LARGE SCALE ENERGY SYSTEMS: THE CASE OF THERMAL POWER PLANT
}

\author{
Niki Sissamperi (D), Dimitrios Koliopoulos (iD \\ University of Patras (Greece) \\ nsissam@upatras.gr,dkoliop@upatras.gr
}

Received October 2020

Accepted January 2021

\section{Abstract}

The aim of this study is to investigate the impact of a constructivist teaching intervention on 6th grade students' cognitive progress on large-scale Energy Generation Systems (EGS), specifically on a Thermal Power Plant (TPP). This intervention was designed according to the constructivist approach for teaching and learning science, and it can be described as an autonomous teaching module appropriate for an elementary science curriculum. With the application of this intervention in real classroom settings, the majority of students were able to construct sufficient technological and scientific knowledge in order to describe and explain the operation of a TPP in qualitative energy terms, as our research data ascertained.

Keywords - Electricity Generation Systems, Elementary education, Energy chain model, Systemic learning, Thermal Power Plant.

\section{To cite this article:}

Sissamperi, N., \& Koliopoulos, D. (2021). How students of primary school understand large scale energy systems: the case of thermal power plant. Journal of Technology and Science Education, 11(1), 129-145. https://doi.org/10.3926/jotse.1137

\section{Introduction}

Since the 1970s, there has been a growing body of research on students' understanding of the concept of energy; this has been under investigation before and/or after teaching interventions at various educational levels and in various contexts (Driver \& Millar, 1986; Lijnse, 1990; Millar 2005; Doménech, Gil-Perez, Gras-Marti, Guisasola, Martinez-Torregrosa, Salivas et al., 2007; Lindsay, Heron \& Shaffer, 2012; Vince \& Tiberghien, 2012; Chen, Eisenkraft, Fortus, Krajcik, Neumann, Nordine et al., 2014; Koliopoulos, 2014). In recent years, there has been an increase in pertinent research that especially focuses on this issue in primary education (Koliopoulos, Aduriz-Bravo \& Ravanis, 2012; Colonnese, Heron, Michelini, Santi \& Stefanel, 2012; Lacy, Tobin, Wiser \& Crissman, 2014; Papadouris \& Constantinou, 2016; Boyer \& Givry, 2018). Nevertheless, research that addresses how primary education students conceive this concept is still limited with regard to the phenomenological field and context of large-scale Electricity Generation Systems (EGS), such as Thermoelectric Power Plants (TPP), Hydroelectric Power Stations (HPS), Wind Turbines (WT), and Photovoltaic Farms (PF). One possible explanation for the scarcity of research in this area is that EGS are usually presented only briefly in traditional formal education curricula, as technological applications for a generic approach of the energy concept, and not as an autonomous 
teaching and learning objective. Given this, there are limited practical reasons that would prompt the investigation of students' potential conceptual challenges.

More recently, however, it appears that certain educational conditions do, in fact, encourage the introduction of EGS in primary education as an autonomous thematic area. One of these conditions is the progressively growing acceptance of the cross-curricular STEM (Science, Technology, Engineering, Mathematics) approach by both educators and educational systems alike. This approach creates a privileged field within which it is possible to include energy-related issues that carry social interest, even at the level of primary education (Wendell, 2014). Assuming that the proper conditions for the systematic introduction of EGS in education are present, then it becomes necessary to explore the various aspects of this new endeavor. These aspects concern, among others, the nature and the characteristics of the pursued knowledge, the goals and limitations that derive from the curriculum, and younger students' cognitive capabilities and challenges. In this research, we mostly address the latter.

In order to explore students' potential cognitive progress regarding the operation of EGS, we designed a teaching intervention in the form of an educational science module for the last year of primary school, and we conducted interviews with participating students, aged 11 to 12-years-old. Our research objectives include (a) the brief presentation of the theoretical framework that determined the design of the intervention, (b) the description of the structure and content of the intervention, and (c) the presentation of the method and results of this empirical research regarding students' cognitive progress level on EGS and, more specifically, on the operation of the TPP.

\section{A Framework for Analyzing and Designing Science Teaching Interventions and Activities}

The teaching intervention we designed is based on a transposition procedure of scientific knowledge (reference knowledge) into knowledge to be taught (school knowledge). In the French educational research tradition, this process is characterized as a "didactic transposition" (Arsac, Chevallard, Martinand \& Tiberghien, 1994). Thus, through this didactic transposition, content analysis of a series of Greek and international science curricula on the energy concept led to the formation of a science curricula classification. According to this classification, these curricula can be categorized into three broad conceptual frameworks for the relevant type of transposition of knowledge into its school version: the "traditional" framework, the "innovative" framework, and the "constructivist" frameworks of the science curriculum (Koliopoulos \& Constantinou, 2012; Delegkos \& Koliopoulos, 2020).

The "innovative" framework mainly concerns the curriculum's conceptual content and an epistemological analysis of required school knowledge. Within this context, energy constitutes a broad thematic/conceptual unit, or an organizing principle of the entire curriculum, and it is introduced as a primary concept, wherein the unifying and trans-phenomenological character is emphasized through the notions of storage, transfer, transformation and conservation. In the particular case of EGS, we suggest that the reference knowledge derives from the field of Engineering Thermodynamics. More precisely, dealing with EGS requires combining the following four conceptual dimensions of this reference knowledge (Sissamperi \& Koliopoulos, 2015):

1. The phenomenological dimension, which contains the definition of the phenomenological characteristics of the studied technological systems (TPP, HPS, WT, etc.). Within this dimension, school knowledge mainly involves the identification and description of the external features of EGS, either by using photos or visiting the real EGS.

2. The technological dimension, which distinguishes the different parts of the technological systems and also clarifies the structure and the operation of system components. The size of these systems and their complexity are their inherent characteristics. In order to highlight these characteristics, and to deal with the difficulties arising from the limitations of children's thinking, three-dimensional EGS representational models need to be constructed. These representational models should be operational, in that students should be able to construct ideas not only to understand the structure of EGS, but their operation as well. 
3. The scientific dimension, which describes, mainly in qualitative terms, the thermodynamic systems on which the storage, the transfer and the transformations of energy occur. Within this dimension, the aim of a teaching intervention could be students' construction of the semi-quantitative conceptual model of energy chains, as this model is an appropriate form for teaching energy at different educational levels. The conceptual model of the energy chains is (a) a valid epistemological transformation of scientific knowledge, since it is directly linked to the nature and the characteristics of the first and second laws of thermodynamics (Lemeignan \& Weil-Barais, 1994; Domenech et al., 2007), (b) to a certain level, compatible with the linear causal reasoning (Tiberghien, 2004), activated by students from a very early age and (c) applied successfully in various teaching programs at various levels of education (Chen et al., 2014).

4. The environmental dimension which directly connects to the scientific dimension (Vince \& Tiberghien, 2012; Besson \& de Ambrosis, 2014; Johnson \& Cincera, 2019) and, at the same time, describes the environmental impact of operating different natural and technological systems. Proposed school knowledge within this dimension includes: (i) knowledge concerning children's familiarity with the environmental problems mentioned above which are mainly related to TPP operation, and (ii) knowledge highlighting the issue of sustainability of natural resources and related to the environmental impact of EGS, which operate with renewable energy.

The "constructivist" framework of the science curriculum -which can co-exist alongside the "innovative" framework- is mainly characterized by the inherent integration of students' mental representations during instruction (Fensham, Gunstone \& White, 1994; Tiberghien, 1997; Leach \& Scott, 2003). To begin with, research highlights that even very young students are capable of constructing systemic thinking skills (Jacobson \& Wilensky, 2006), which are the kind of skills that align with the systemic nature of technological and scientific knowledge required for describing and explaining EGS (Frank, 2000). Additionally, it appears that the systemic thinking as cognitive ability can be cultivated through the systemic approach of complex technological systems (Ben-Svi Assaraf \& Orion, 2010; Hmelo-Silver \& Azevedo, 2006). In this context, the teaching suggestions of Van Huis and Van der Berg (1993) and Jewett (2008) are of particular interest, since they refer to the teaching of the energy concept in secondary school. In addition, relevant research indicates that if preschool and elementary school students activate linear causal reasoning, they can achieve the construction of a qualitative model for the description and the scientific explanation of simple and small-scale energy systems (e.g., "lighting a bulb with a battery") (Koliopoulos, 2013). More specifically, there is evidence suggesting that students at all educational levels can describe many simple natural and/or simple technological systems either as a chain of objects in terms of their function (e.g. "the bulb lighting is due to the battery"), or as a chain of objects in terms of their distribution, such as a transfer of an action (e.g. "the battery is supplying energy to the lamp, and it lights up") (Lemeignan \& Weil-Barais, 1994; Tiberghien \& Megalakaki, 1995; Delegkos \& Koliopoulos, 2020). Such pre-energy mental representations are spontaneously activated, even before a teaching intervention, and can be used as pre-existing conceptions for the construction of school knowledge for the energy concept. Thus, we hypothesize that children aged 11 to 12 years-old can use the aforementioned school knowledge characteristics to describe and explain not only the operation of small technological systems used in school laboratories, but also the EGS or at least their respective representational models as well.

Introducing a series of proper, interrelated "problem-situations" can prompt students' mental representations to emerge, so that they can subsequently be processed during instruction (Boilevin, 2005). The aim in engaging students through these activities is to gradually transition students' mental representations toward more sophisticated representations that, in turn, more accurately reflect suggested school knowledge. More precisely, this series of interrelated problem-situations are designed through "hypotheses based on the elements of students' prior knowledge, from which they can construct new knowledge, and not only on the prior knowledge which has to be modified" (Tiberghien, 1997: page 359). The key characteristic of the problem-situations included in this suggested teaching intervention is that they engage students in discussions about interactions between various dimensions of school knowledge. 
Establishing relationships between the world of objects and events (phenomenological dimension) and its various types of modelling (technological, scientific, environmental dimensions) seems to lead students toward building new knowledge through categorizations, causal explanations and other mental tools they employ (Tiberghien, Vince \& Gaidioz, 2009; Ruthven, Laborde, Leach, \& Tiberghien, 2009). In the case of this study, the problem-situations were designed with the assumption that 11-12 year old students, by using basic systemic thinking and activating their linear causal reasoning, are capable of constructing precursory, and mainly qualitative, explanatory models for the structure and operation of particular EGS, within every dimension of the required knowledge.

\section{The Teaching Intervention: Cognitive Objectives, Structure and Content}

The cognitive objectives of the particular teaching intervention built for this study were set up in such a way that prompted students to work through each of the four dimensions of knowledge construction for EGS. Thus, for the (a) phenomenological dimension, the objective was for students to recognize and name different types of EGS; for the (b) technological dimension, the objective was for students to be able to distinguish between the different parts of each EGS and describe the operation of each of these parts, for the (c) scientific dimension, the objective was for students to be able to describe the connection and interaction between particular key components of an EGS, using the semi-quantitative energy model of energy chains, and for the (d) environmental dimension, the objective was for students to be able to identify the environmental impact of operating an EGS. The conceptual content of the teaching intervention was structured into four thematic units: (A) What is an EGS? - The TPP, (B) Renewable energy sources, (C) Measurement of energy in EGS and (D) EGS and daily life. Each unit consists of 2 or 3 subunits, which each utilized a main problem-situation to introduce proposed school knowledge. The structure and content (11 subunits) of the teaching intervention appear in Table 1.

\begin{tabular}{|c|c|c|c|}
\hline Unit & Subunit & $\begin{array}{c}\text { School knowledge } \\
\text { (Dimensions of knowledge) }\end{array}$ & Main problem situation \\
\hline \multirow{3}{*}{ A } & 1 & Phenomenological & What's behind the plug? \\
\hline & 2 & Technological & How does a TPP works? \\
\hline & 3 & Scientific & Why the lamps light up? \\
\hline \multirow{3}{*}{ B } & 4 & $\begin{array}{l}\text { Environmental } \\
\text { Technological } \\
\text { Scientific }\end{array}$ & $\begin{array}{l}\text { How can we reduce or avoid air pollution generated by } \\
\text { the TPP? }\end{array}$ \\
\hline & 5 & Technological & How does a HPS work? \\
\hline & 6 & Scientific & How is a W'T made, and how does it is work? \\
\hline \multirow{3}{*}{$\mathrm{C}$} & 7 & $\begin{array}{l}\text { Technological } \\
\text { Scientific }\end{array}$ & $\begin{array}{l}\text { What will happen to a plant if we need to use more } \\
\text { electrical devices? What will happen to a HPS if we } \\
\text { need to use high power lamps? }\end{array}$ \\
\hline & 8 & $\begin{array}{l}\text { Technological } \\
\text { Scientific }\end{array}$ & $\begin{array}{l}\text { How do we measure the amount of energy transferred } \\
\text { from a HPS? }\end{array}$ \\
\hline & 9 & $\begin{array}{l}\text { Technological } \\
\text { Scientific }\end{array}$ & $\begin{array}{l}\text { How do we pay the Power Supply Company? How } \\
\text { much energy is transferred to the lamps of the } \\
\text { classroom? Can we measure it, and if so, how? }\end{array}$ \\
\hline \multirow[t]{2}{*}{$\mathrm{D}$} & 10 & $\begin{array}{l}\text { Environmental } \\
\text { Technological } \\
\text { Scientific }\end{array}$ & Why do we change the incandescent lamps? \\
\hline & 11 & Phenomenological & Let's visit a real HPS! \\
\hline
\end{tabular}

Table 1. The structure and content of the teaching intervention

In order to overcome students' difficulties in understanding the complexity of these systems, a number of different representational models of EGS were used in this intervention. Tala (2008) emphasizes that "it is through the material models that the concepts of theories get empirical meanings" (page 279). Some of these models help students construct and handle conceptual models of abstract and non-observable physical entities (Harrison \& Treagust, 2000; Tobin, Lacy, Crissman \& Haddad, 2018). Students consulted 
the following representations, in increasing order of EGS idealization: (a) Illustrations of real EGS (Figure 1), (b) Two-dimensional models of EGS (Figure 2), and (c) Three-dimensional operational models of EGS. Figure 3 illustrates a prototypical model of a TPP with visible basic subsystems, such as burner, boiler, turbine, generator, and (b) abstract representations (EGS energy chain - Figure 4).

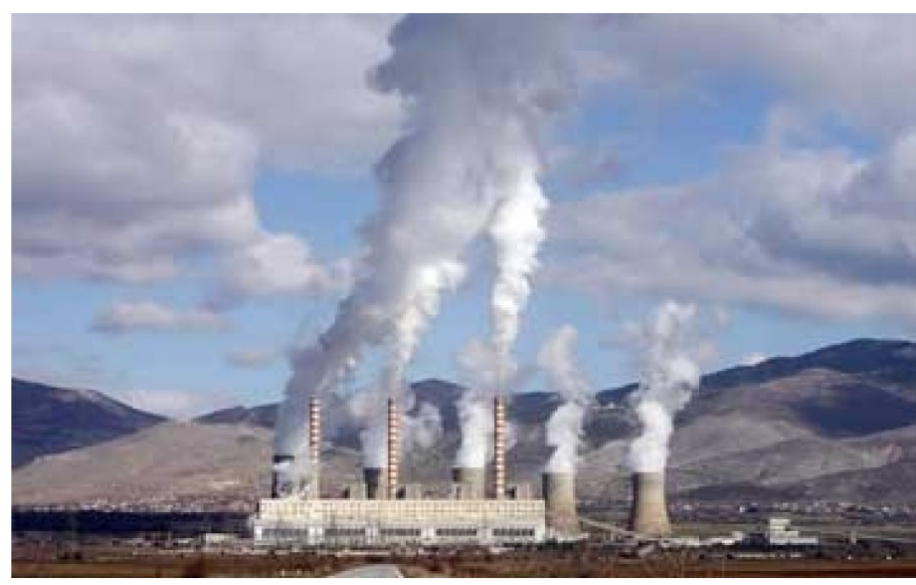

Figure 1. Photo of a real TPP (Kozani, Greece)

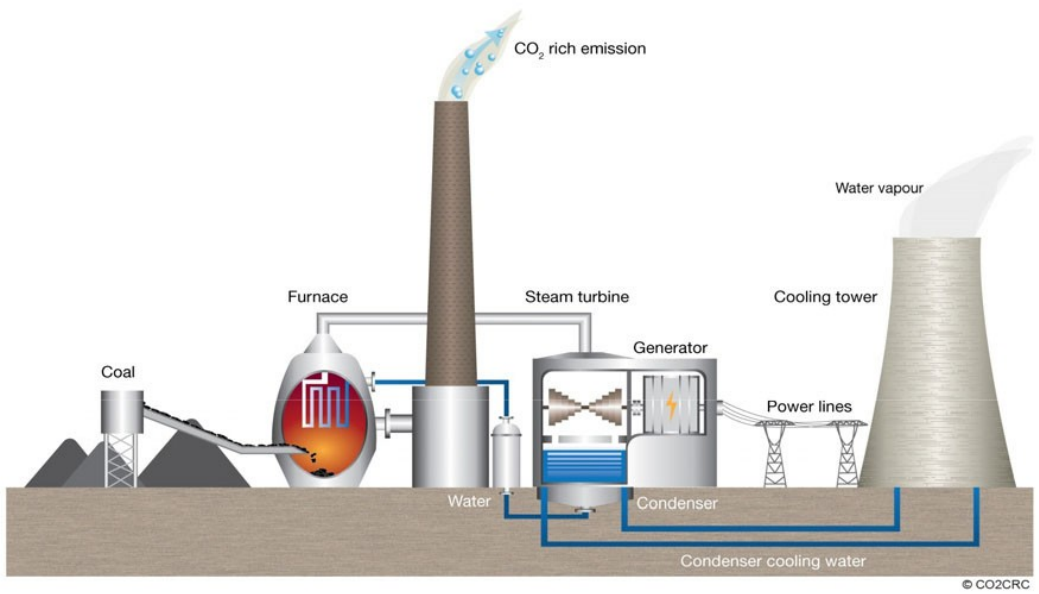

Figure 2. A 2-D representation of a TPP

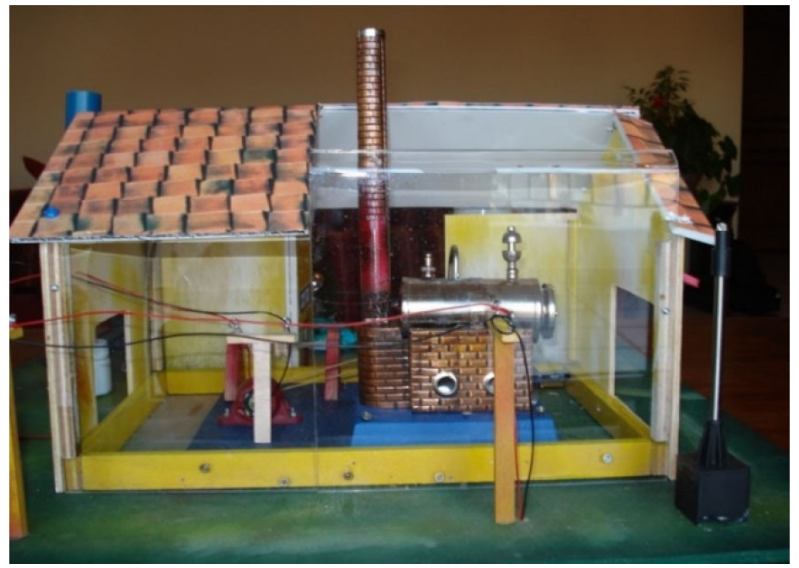

Figure 3. A prototypical 3-D representation of a TPP 


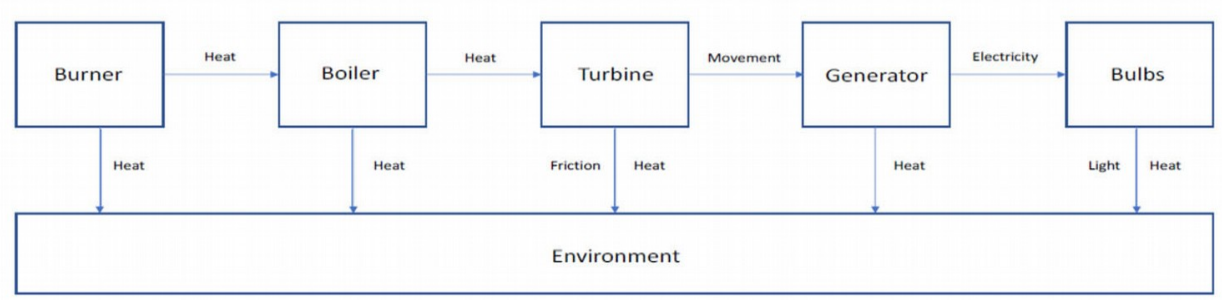

Figure 4. Schematic representation of the energy chain corresponding to the energy description of a TPP model

Students filled out also a worksheet for each subsection, which were designed in a manner that simulated the worksheets of their existing textbooks. The aim was for students to perceive this worksheet as a familiar feature of their lessons, controlling for the ways in which the final result might be affected by factors external to the suggested knowledge. Additionally, the worksheets were designed to be interesting, pleasant, comprehensible, and brief enough in order to be completed by as many students as possible. The language used in the titles, as well as in the rest of the document, was of moderate formality (Dimopoulos, Koulaidis \& Sklaveniti, 2005), in order to achieve sufficient readability. These worksheets included (a) questions students had to answer about the observed natural and technological phenomena, (b) activities to construct symbolic representations of the energy chain model for the various EGS, (c) problems that helped students approach school knowledge more thoroughly, and (d) brief passages to read, containing information about technological topics, or issues of everyday life.

A typical example of a unit included in the teaching intervention is that of subunit 4, "How can we reduce or avoid air pollution generated by the TPP?". Within this unit we attempted to activate three dimensions of required school knowledge (technological, scientific, and environmental), using the environmental issue of air pollution as a triggering event. More specifically, students discussed and identified the root of the problem (carbon dioxide emissions), while prompted to measure the carbon dioxide levels before, during, and after the operation of the TPP representational model (Figure 3), in three different positions: in close proximity to the TPP model, at a distance of one meter, and at a distance of five meters. Based on these measurements, they came to some initial conclusions and, afterward, studied the supplementary document labeled "Scientific reposting." In the second activity, we posed the crucial question "How are pollutants created?" Consequently, students were expected to seek the answer in the system's technological description, correlating pollutants to conventional fuel combustion. In the third activity, we attempted to focus the discussion on the kind of technological system that could replace the burner, or other components, in order to tackle this environmental issue. The fourth and fifth activities aimed for student discussion on the energy-related aspect of the pollution issue, in order to realize its quantitative nature and identify how it is connected to our energy needs. Therefore, our assumption was that each of these problem-situations would lead students toward the construction of the prerequisite multi-dimensional knowledge to sufficiently deal with these particular problems.

\section{Methodological Framework}

The main research question was posed as follows: Is it possible for 11 to 12 -year-old students to make progress in their cognition of large scale and complex EGS, in order to be able to describe and explain the operation of these systems? In the present study, the research question is in reference to the TPP alone. The following questions iterate the main research question:

After their participation in our teaching intervention, were these students able to think through a multi-dimensional framework to:

1. Recognize and name different types of EGS (phenomenological dimension)?

2. Distinguish between the different parts used to construct each EGS and also describe the operation of these parts (technological dimension)? 
3. Describe the connection and interaction between the components of each EGS using a qualitative/semi-quantitative energy model (scientific dimension)?

4. Identify the environmental impact of each EGS operation (environmental dimension)?

The strategy of this research is pre-experimental (Cohen, Manion \& Morrison, 2007), the essential feature of which is to intentionally control and manipulate any conditions that define the instances the researchers are interested in. Our work belongs to so-called feasibility (Astolfi, 1993) or developmental studies (Lijnse, 1995) which mainly focus on examining the potential for students' cognitive progress within an in vitro, or research, environment, rather than their cognitive progress in real, or in vivo, teaching conditions.

The sample consisted of 21 students (13 girls and 8 boys) of a public primary school in a suburban district. All students were between 11 and 12 years old, which is typical for the last year of primary school. The teaching intervention was applied by one of the two researchers in order to minimize the "instructor" effect. All students were informed of the reason and the purpose of the research process in advance of the intervention.

In order to evaluate students' cognitive progress, individual pre- and post- guided interviews were used, which were recorded and transcribed. Each interview lasted approximately 30 minutes. The interviews included eight questions that related to the TPP, and implicated the four dimensions of knowledge (phenomenological, technological, scientific and environmental). The post-interview developed in two parts. The first part included the exact questions presented in Table 2. The second part included questions that referred to other types of EGS (the HPS, which was a teaching objective, and the PF, which was not a teaching objective). The analysis of the data collected during the second part of the interview did not concern the current study. Additionally, this study did not aim to investigate students' representations connected to teaching intervention unit $\mathrm{C}$ (subunits 7, 8, and 9). Unit $\mathrm{C}$ addresses the quantitative approach of a HP through the use of the energy chain model.

\begin{tabular}{|c|c|c|}
\hline No & Dimensions of knowledge & Question \\
\hline 1 & Phenomenological & $\begin{array}{l}\text { What do you see in the picture? Do you know what it is? What is it } \\
\text { called? (TPP Photo) }\end{array}$ \\
\hline 2 & Phenomenological & $\begin{array}{l}\text { What do you see here? Do you know what is it? What is it called? (3-D } \\
\text { representation of TPP - Fig 3) }\end{array}$ \\
\hline 3 & Technological & $\begin{array}{l}\text { What is this? (Identify each of the "burner", "boiler", "turbine", and } \\
\text { "generator" of the TPP 3D representation - Fig 3) }\end{array}$ \\
\hline 4 & Technological & $\begin{array}{l}\text { What is the function of this? (Identify each of the "burner", "boiler", } \\
\text { "turbine", and "generator" of the TPP 3D representation - Fig 3) }\end{array}$ \\
\hline 5 & Scientific & Why do the lamps turn on? (TPP 3D representation - Fig 3) \\
\hline 6 & Scientific & $\begin{array}{l}\text { Place the cards in the correct order of use. Explain why you organised } \\
\text { them this way (Cards with the words "burner", "boiler", "turbine", } \\
\text { "generator", and "lamps" written on them and arrow-shaped cards } \\
\text { were given) }\end{array}$ \\
\hline 7 & Scientific / Environmental & $\begin{array}{l}\text { It appears that the TPP creates air pollution, however the electric } \\
\text { devices are important in our lives. What solution or solutions would } \\
\text { you suggest so the TPP works without creating pollution? (TPP 3D } \\
\text { representation - Fig 3) }\end{array}$ \\
\hline 8 & Scientific / Environmental & $\begin{array}{l}\text { When we leave the classroom for a break, we turn off the lights. Why } \\
\text { do we do this? }\end{array}$ \\
\hline
\end{tabular}

Table 2. The content of the interview questions

\section{Research Results}

To analyze the data collected from the interviews, we used the following classification to code students' answers: (a) sufficient answers were fully compatible with the suggested school knowledge content (b) intermediate answers were compatible with the suggested school knowledge content, but were incomplete 
in formulation or included elements beyond this content (c) insufficient answers were completely incompatible with the suggested school knowledge content, and (d) no answer was provided. The results presented here are derived from the quantitative results' analysis (tables of absolute frequencies of the categories that have been formed from the students' answers and justifications), as well as from the qualitative analysis (instances of justifications provided by the students).

\subsection{Phenomenological Dimension of Knowledge}

The first two questions of the interview investigated students' mental representations about the phenomenological characteristics of a TPP. The main difference between these questions was the phenomenological representation of a TPP, which students had to observe and report on. Question 1 explored whether students could recognize and name a photo of a real TPP as such, while question 2 explored whether students could recognize and name a TPP when they are presented with a 3D model of one.

Based on the responses before the teaching intervention in the pre-test interviews, it can be concluded that most students could not effectively recognize and name either a real TPP or 3D model of a TPP. After the teaching intervention, however, we noticed students' transition towards efficient answers, as expected (Table 3). Changes in the opposite direction, that is, toward less efficient answers, were not observed. This finding is statistically significant (Test Wilcoxon, question $1: Z=-3.542, p<0.001$, question $2: Z=-3.035, p<0.01$ ).

\begin{tabular}{|l|c|c|c|c|}
\hline & $\begin{array}{c}\text { Question 1 } \\
\text { Pre-test }\end{array}$ & $\begin{array}{c}\text { Question 2 } \\
\text { Pre-test }\end{array}$ & $\begin{array}{c}\text { Question 1 } \\
\text { Post-test }\end{array}$ & $\begin{array}{c}\text { Question 2 } \\
\text { Post-test }\end{array}$ \\
\hline Sufficient & - & - & 12 & 15 \\
\hline Intermediate & 2 & 2 & 5 & 2 \\
\hline Insufficient & 16 & 12 & 4 & 4 \\
\hline No answer & 3 & 7 & - & - \\
\hline Total & 21 & 21 & 21 & 21 \\
\hline
\end{tabular}

Table 3. The sufficiency of mental representations in responses to questions $1 \& 2$

\subsection{Technological Dimension of Knowledge}

Questions 3 and 4 investigated students' mental representations about the technological dimension of knowledge. Students' responses before the teaching intervention in the pre-test interviews indicated that they were not only unaware of the parts that construct the TPP, but also unaware of their operation (Table 4). Specifically, during the pre-test, students provided exclusively insufficient answers or didn't answer these questions. The common characteristics between these answers were that students (a) were unaware of the components of the TPP representational model, (b) did not perceive the representational model of TPP as a whole system, and (c) as a consequence of (b), could not identify functionality of these components.

\begin{tabular}{|l|c|c|c|c|}
\hline & $\begin{array}{c}\text { Question 3 } \\
\text { Pre-test }\end{array}$ & $\begin{array}{c}\text { Question 4 } \\
\text { Pre-test }\end{array}$ & $\begin{array}{c}\text { Question 3 } \\
\text { Post-test }\end{array}$ & $\begin{array}{c}\text { Question 4 } \\
\text { Post-test }\end{array}$ \\
\hline Sufficient & - & - & 9 & 14 \\
\hline Intermediate & - & - & 11 & 2 \\
\hline Insufficient & 12 & 19 & 1 & 4 \\
\hline No answer & 9 & 2 & - & 1 \\
\hline Total & 21 & 21 & 21 & 21 \\
\hline
\end{tabular}

Table 4. The sufficiency of mental representations in responses to questions $3 \& 4$

However, after the teaching intervention, the majority of students provided either sufficient $(9 / 21)$ or intermediate (11/21) answers to question 3 in the post-test interviews. Changes toward the opposite direction, that is, toward less efficient answers, were not observed. This finding is statistically significant (test Wilcoxon $Z=-3.017, \mathrm{p}<0.01$ ). From these answers, it appears that students either learned all, or 
most, of the parts of the representational model of TPP. Additionally, the majority of students provided either sufficient $(14 / 21)$ or intermediate $(2 / 21)$ answers to question $4(16 / 21$ in total) in the post-test interviews. This finding is also statistically significant (test Wilcoxon $\mathrm{Z}=-3.557, \mathrm{p}<0.001$ ). After the teaching intervention, we also noticed that students were able to distinguish between the representational model parts of the TPP, while also describing their functions. Further, students were able to describe the operation of the parts of the representational model of TPP, even if, in some cases they didn't remember their respective names.

Student's M4 response to question 3 in the post-test interview is a typical example of these observations:

"Number one is the burner and there is fire inside the burner...; the heat is transferred to number two, and therefore the water evaporates due to the warmth; number two is the boiler and thus the steam is transferred through the pipe and goes to number three...; number three is the turbine and, due to the steam, the turbine begins to turn while the movement goes to number four, which is the boiler... hm... no, that's wrong, it is the generator...; the generator converts the motion to electricity, and electricity, through the wires, is transferred to the lamp and the lamp turns on."

This student gave the same answer to question 4 in the post-test interview: "The same applies here as in question 3." From this, we can claim that the scientific dimension of knowledge (school knowledge for energy) did not work completely autonomously, but rather also attributed meaning to the technological dimension of knowledge (recognition of technological components that belong to a technological system).

\subsection{Scientific Dimension of Knowledge}

Questions 5 and 6 investigated students' mental representations about the scientific dimension of knowledge.

\begin{tabular}{|l|c|c|c|c|}
\hline & $\begin{array}{c}\text { Question 5 } \\
\text { Pre-test }\end{array}$ & $\begin{array}{c}\text { Question 6 } \\
\text { Pre-test }\end{array}$ & $\begin{array}{c}\text { Question 5 } \\
\text { Post-test }\end{array}$ & $\begin{array}{c}\text { Question 6 } \\
\text { Post-test }\end{array}$ \\
\hline Sufficient & - & - & - & 10 \\
\hline Intermediate & - & - & 7 & 7 \\
\hline Insufficient & 21 & 21 & 14 & 4 \\
\hline Total & 21 & 21 & 21 & 21 \\
\hline
\end{tabular}

Table 5. The sufficiency of mental representations in responses to questions 5 \& 6

As shown in Table 5, all of the students gave insufficient answers to both questions 5 and 6 in the pre-test interview, and the majority gave ineffective answers to these questions (5 in particular), in the post-test interview. The results included answers that (i) either had no reference to the concept of energy and were to a great extent, phenomenological or tautological answers, or (ii) embedded energy-related concepts as an expression of pre-energy mental representation.

A typical example of an insufficient response within category (i) was student M17's answers. Responding to question 5 in the pre-test interview, this student said: "I see how you have connected the machines with some wires. The wires produce current, which moves from the vehicles to the wires, and the wires transfer it to the lamps." Moreover, in question 6 in the pre-test interview, the same student insufficiently justified the way they ordered the cards to represent the TPP (surroundings, arrow, burner, generator, arrow, turbine, arrow, boiler, arrow, lamp):

"I started with the surroundings because the current is produced by the surroundings, then I moved on to the coal... I saw the order you had placed them and then I added the surroundings at the beginning, and I placed the lamp because the current goes to the lamp."

As for an insufficient response within category (ii), a typical example is that of student M3's answer. Responding to question 5, this student said: "When it moves and produces energy, the machines connect, and the energy reaches the wires. The wires at some point connect on the maquette, and the energy goes to the lamp and turns it on." Additionally, in question 6 the same student insufficiently justified way they 
ordered the cards to represent the TPP (generator, arrow, turbine, arrow, boiler, arrow, burner, lamp, arrow, surroundings):

"I believe that the generator is machine 1; then the energy goes to the turbine which is macbine 2; then the energy leaves toward machine 3 that is the boiler; the boiler sends the energy to the burner; then, the energy goes to the lamp and goes to the surrounding."

The examples above show that students, in both categories, did use elements of systemic thinking, as well as linear causal reasoning. However, these responses were classified as insufficient because they (a) used imprecise or incorrect conceptions of the components included in the technological system and/or (b) expressed pre-energy conceptions that mainly reflected only a vague nature of the intermediate action that connects the source to the receiver.

After the teaching intervention, however, several of the students' responses made the transition toward intermediate and sufficient explanations. In responses to question 5, the majority of students continued to provide insufficient answers, while some did provide intermediate responses $(7 / 21)$. Nevertheless, this finding is also statistically significant (test Wilcoxon $\mathrm{Z}=-2.226, \mathrm{p}<0.05$ ). Student M6 provided a typical example of an intermediate response to this question:

"Because at the turbine there is kinetic energy, and because this kinetic energy is transferred to the generator, and from that point, it converts to electric current. That electric current is transferred through the wires, and this is how the lamps turn on."

These results would have been discouraging without the more efficient responses to question 6 which sketched a considerably different picture. As shown in Table 5, the majority of students properly constructed the graphic representation of the energy chain, giving a sufficient $(10 / 21)$ or an intermediate response $(7 / 21)$, for a total of $(17 / 21)$ efficient responses. This finding is statistically significant (test Wilcoxon $\mathrm{Z}=-2.226, \mathrm{p}<0.05)$. According to the following example, the same student (M6) made a transition toward a sufficient response. They now correctly justified the correct order in which they have placed their cards of technological components and arrows/forms of transferred energy (burner, heat, boiler, movement, turbine, movement, generator, electricity, lamp, light/heat, surroundings):

"First I put the burner, which is an energy storage. All chains start with an energy storage. Afterward, when the combustive material burns, the heat is transferred: it goes to the boiler, the boiler converts the beat into movement; afterward it goes to the turbine and it produces more movement; afterward, the movement is driven toward the generator, which converts the movement into electricity; the electricity goes to the lamp and converts it into light/ heat that goes to the surroundings."

Based on the examples mentioned above, we assumed that the majority of students gained the capability to construct a qualitative chain energy model to explain the function of the TPP representational model. Students' poor verbal and/or written ability to express their mental representations, which can be expected at this age, could explain the considerable difference in student performance between their answers to questions 5 and 6 . On the contrary, the use of a "language" based on energy representations, such as the energy chains, probably offered a more semiotically stable context, within which students could express their newly constructed knowledge.

\subsection{Environmental Dimension of Knowledge}

Questions 7 and 8 investigated students' mental representations within the environmental dimension of knowledge.

As shown in Table 6, before their participation in the teaching intervention, most students provided mainly insufficient answers to both questions 7 and 8 , as they failed to connect the environmental problem and its solution(s) to the TPP's structure and operation. Typical examples of insufficient answers to question 7 in the pre-test interviews included the following: "I would suggest installing a filter in the plant, so they wouldn't pollute the environment that much," from student M6; and "The small tube that emits smoke to the environment should not exist," from student M14. Meanwhile, respective examples for answers to question 8 in the pre-test interviews included: "To save money... we won't give the electric 
company that much money," from student M1; and "We obviously do not need it since we are in a different place," from student M8.

\begin{tabular}{|l|c|c|c|c|}
\hline & $\begin{array}{c}\text { Question 7 } \\
\text { Pretest }\end{array}$ & $\begin{array}{c}\text { Question 8 } \\
\text { Pretest }\end{array}$ & $\begin{array}{c}\text { Question 7 } \\
\text { Posttest }\end{array}$ & $\begin{array}{c}\text { Question 8 } \\
\text { Posttest }\end{array}$ \\
\hline Sufficient & 1 & - & 13 & 5 \\
\hline Intermediate & 3 & 1 & 7 & 14 \\
\hline Insufficient & 14 & 20 & 0 & 1 \\
\hline No answer & 3 & - & 1 & 1 \\
\hline Total & 21 & 21 & 21 & 21 \\
\hline
\end{tabular}

Table 6 . The sufficiency of mental representations in responses to questions $7 \& 8$

After the teaching intervention, the majority of students did make a transition toward sufficient answers to both questions 7 and 8 in the post-test interview. This finding is statistically significant for both question 7 (test Wilcoxon $Z=-3.624, p<0.05$ ) and question 8 (test Wilcoxon $Z=-4.065, p<0.05$ ). Most students shifted effectively toward providing intermediate responses to question 8 . It appears that students did not associate environmentally friendly behaviors (i.e., turning off the lights) with the structural and operational features of a TPP. Yet, in response to question 7 they were in a position to suggest, as a solution to the environmental problem, a change in the type of electricity production by proposing renewable energy sources to replace the TPP, and specifically referred to hydroelectric power stations, wind farms and photovoltaic farms.

Two typical sufficient answers to the post-interview questions included the following. To question 7 , student M8 replied:

"We would use the hydroelectric power station [more] because it uses a renewable material that can be used many times, and it does not produce as many pollutants as the thermoelectric. But we can also use the wind farms, the wind turbines that produce energy from the air"

while to question 8, student M1 replied:

"When the lamps are turned on, they spend some Watts that we pay for. We pay the energy we use, therefore, we turn them off so we do not waste the energy when we do not need them...; also, not to pollute the environment, not to burden the environment, because for the plants to produce energy they pollute the environment with the fumes that come out, if it is produced by a thermoelectric plant."

\section{Discussion and Conclusions}

In this research, we attempted to illustrate that designing a teaching intervention for 11 and 12 -year-old students aiming for their understanding of complex technological systems, such as the EGS is, in fact, an attainable goal. More specifically, we focused on presenting how our proposed teaching intervention (a) is based on an epistemologically valid didactic transposition of the required knowledge and (b) leads participating students toward a respective cognitive progress in reference to this knowledge.

Concerning the didactic transposition of the reference knowledge, we suggest that the required knowledge for the description and explanation of the various EGSs operation is multidimensional, since it consists of at least four dimensions (phenomenological, technological, scientific, environmental). The basic elements of our approach are the following:

1. The teaching intervention that we suggest in this paper is fully compatible with the international trends in STEM and/or technoscience curricula design. According to Tala (2008), technoscience education is a unified science and technology educational approach, which links abstract scientific concepts to each other, and to the physical world; it facilitates the understanding and application of natural laws, and essentially, the construction of scientific knowledge. Teaching energy -with an emphasis on the technological characteristics of the energy system- seems to be an emerging approach in elementary education (Wendell, 2014). 
2. This teaching intervention is based on a systemic approach on science and technological/engineering knowledge. The phenomenological field of EGSs, which consist of large-scale complex technological systems, as well as the concept of energy per se, do, indeed, call for this systemic approach on the field. This is particularly important for introducing young students to the operation of such systems. Domenech et al. (2007), in their emblematic article "Teaching of energy issues: A debate proposal for a global reorientation" give prominence to the systemic nature of the energy concept. Meanwhile Lacy et al. (2014) report the term "Energy Lens" to describe an analytical tool for teaching energy in grades 3-5, and they, too, point out that the in-depth understanding of energy often requires thinking in terms of systems.

3. The energy chain model plays a key role in our teaching sequence, since it facilitates coherence between the phenomenological level and the "theory" level (Tiberghien, 1994; Tiberghien, 1996; Meli \& Koliopoulos, 2019) of knowledge, which, in our case, combines technological, scientific and environmental knowledge dimensions. Both contemporary and older scholarship puts the energy chains or other thermodynamic models with a respective graphical representational power forward as proper explanatory energy models, especially for younger students (Tiberghien \& Megalakaki, 1995; Papadouris \& Constantinou, 2016; Scherr, Harrer, Close, Daane, DeWater, Robertson et al., 2016; Boyer \& Givry, 2018; Kubsch, Nordine, Fortus, Krajcik \& Neumann, 2019; Delegkos \& Koliopoulos, 2020). These models are compatible with linear causal reasoning, common for all learners, regardless of their age (Tiberghien, 2004).

4. The design of all teaching activities is in line with the inquiry-based teaching approach (Minner, Levy \& Century, 2010; Harlen, 2013). In our teaching sequence, this approach is expressed through students' interaction with "problem-situations" that intend to make students connect the phenomenological knowledge dimension (actual EGS, static or functional EGS models) with three other knowledge dimensions: technological (EGS basic components and operation), scientific (qualitative energy model), and environmental (connecting the EGS to environmental pollution). Through these activities, students are called to interact with natural, technological or conceptual models (Tala, 2008; Eilam \& Gilbert, 2014). Research on model-based learning has proven to be an effective approach for teaching energy, mainly when the key issue is understanding of energy in terms of systems (Tobin et al., 2018).

In any case, the epistemological content of the school knowledge mentioned above must be compatible with students' explanatory schemes, which are developed when students confront natural or technological systems. Therefore, regarding the sampled students' cognitive progress, based on the analysis of the results collected from the pre- and post-tests, we can claim that our empirical research illustrated the following:

1. The data presented in Table 3 confirm Qualter's (1995) respective results, in that children, who were between the ages of 11 and 12years old didn't know the term "power station" and didn't recognize the phenomenological characteristics of a TPP. Following their participation in the teaching intervention, the majority of students seemed to recognize the TPP (or the TPP representational model) as a complex operational technological system that relates to energy transfer. This progress is attributed to students' constant interaction with the various static or dynamic EGS models (subunits 1-10) as well as their experience visiting the hydroelectric power station, where they were able to easily recognize the station's different areas and basic technological equipment. Also, this conclusion derives except from the data included in Table 3, as well as from complementary results that were collected during the teaching intervention but are not objectives of this work.

2. The data shown in Table 4 suggest that after the teaching intervention, the majority of students perceived a static TPP model as a whole system, within which the parts interact. These results confirm the evidence presented in other research works suggesting that students of this age are in a position to approach complex technological systems using their advanced systemic capabilities (Evagorou, Korfiati, Nicolaou \& Constantinou, 2009; Lippard, Lamm, Tank \& Choi, 2019). This 
finding also confirms Malandrakis's (2007) research results. Additionally, as shown in the qualitative data collected, our most interesting research finding was students' need to recognize and describe the various components of the TPP representational model by using an energy language. In other words, the qualitative model of energy chains not only worked as a proper, autonomous explanatory model for the operation of EGS, but also attributed meaning in the identification of the technological components as a whole operational system. The particular design of our teaching intervention worked toward this direction: the various subunits introduced the respective technological elements of the EGS that were followed by their energy explanation (e.g. subunits $2 / 3$ and subunits $5 / 6$ ).

3. Regarding the scientific dimension of school knowledge, Table 5 revealed that several students successfully made the transition from insufficient to intermediate and sufficient answers, according to the nature of each question. Some of the students who improved toward sufficient energy chain representations may have already constructed pre-energy mental representations prior to the teaching intervention (Lemeignan \& Weil-Barais, 1994; Koliopoulos \& Ravanis, 2001). Our study showed that such representations, which ordinarily appear when students are called to explain the operation of simple technological devices, can be reproduced, or can develop, even in cases of complex technological systems, like the EGS models. These original research findings indicate that it is, indeed, possible for students to overcome the difficulties mentioned in Solomon's (1985) work, in which it was posited that students of this age were unable to grasp the concept of energy in complex systems as EGS. Other research also confirms that students can, in fact, approach a qualitative form of energy-related scientific knowledge in the context of a complex technological system. Dalapa, Vayena, Sissamperi and Koliopoulos (2019) have confirmed that students of this age can apply the energy chain model to qualitatively explain the operation of a hydroelectric power station 3-D model after a shorter teaching intervention during an out-of-school project. It has also been shown that 12 and 13-year-old students are capable of presenting cognitive progress through the construction of a semi-quantitative energy explanation of an operating car, which involves a complex technological system (Stavropoulos \& Koliopoulos, 2019; Stavropoulos, Lavidas \& Koliopoulos, 2019).

4. According to Table 6, the majority of students were unable to correlate air pollution with the operation of EGS prior to the teaching intervention. These findings are consistent with other studies demonstrating that students have alternative conceptions not only about issues related to the social use of energy (Solomon, 1985; Skamp, Boyes, Stanisstreet, Rodriguez, Malandrakis, Forther et al. 2019), but also about the advantages and disadvantages of using different sources of electricity generation (Bodzin, 2012). After the teaching intervention, the results did indicate a transition of students' conceptions from insufficient toward intermediate and sufficient answers; however, the percentage of students that managed to connect environmental perspectives or actions to the operation of EGS was still small. This result may derive from the limited emphasis placed on the environmental dimension of knowledge (in only subunits 4 and 10). We can assume that students who improved toward sufficient answers had efficiently constructed elements of both the technological and scientific dimensions of knowledge. This hypothesis refers to how coherence level of the constructed school knowledge affects students' performance and should be confirmed through the use of more sophisticated statistical methods that were not applicable in this study, given the rather small sample of students. Yet, every research endeavor intrinsically carries elements that can introduce doubt. A problem presented by default in feasibility or developmental research (Lijnse, 1995) is the common use of convenient samples which are used to confirm or reject cognitive hypotheses are usually not sufficient for generalizable research outcomes to the respective population. In such cases, we mostly see case studies that are particularly suited to illustrate (a) the attempted didactic transposition of the reference knowledge to school knowledge and (b) the potential for the construction of this knowledge, rather than its widespread diffusion. 
Therefore, a complementary direction in which to take the current research would be its extension to a broader base of actual classes from various socio-economic backgrounds. At the same time, pertinent research could explore the potential to penetrate students' thinking patterns during the teaching intervention, asking questions like: "How do students think while these activities take place?" and "Which teacher-students and/or student-student interactions formulate students' thinking?" Such research questions can be addressed merely by qualitative methodological approaches, like class observation, and could greatly contribute to a more profound interpretation of the results presented in this research.

\section{Declaration of Conflicting Interests}

The authors declared no potential conflicts of interest with respect to the research, authorship, and/or publication of this article.

\section{Funding}

The authors received no financial support for the research, authorship, and/or publication of this article.

\section{References}

Arsac, G., Chevallard, Y., Martinand, A., \& Tiberghien, A. (1994). La transposition didactique à l'épreuve (The didactic transposition under investigation). La Pensée Sauvage.

Astolfi, J.P. (1993). Trois paradigmes pour la recherche en didactique (Three paradigms for research in Didactics). Revue Française de Pédagogie, 103, 5-18. https://doi.org/10.3406/rfp.1993.1293

Ben-Zvi Assaraf, O., \& Orion, N. (2010). System Thinking Skills at the Elementary School Level. Journal of Research in Science Teaching, 47(5), 540-563. https://doi.org/10.1002/tea.20351

Besson, U., \& de Ambrosis, A. (2014). Teaching energy concepts by working on themes of cultural and environmental value. Science \& Education, 23(6), 1309-1338. https://doi.org/10.1007/s11191-013-9592-7

Bodzin, A. (2012). Investigating urban eighth-grade students' knowledge of energy resources. International Journal of Science Education, 34(8), 1255-1275. https://doi.org/10.1080/09500693.2012.661483

Boilevin, J-M. (2005). Enseigner la physique par situation problème ou par problème ouvert (Teaching physics through problem - situations or open problems). Aster, 40, 13-37.

https://doi.org/10.4267/2042/8854

Boyer, A., \& Givry, D. (2018). Développement d'un modèle de chaîne énergétique pour aider les élèves à adopter une vision globale de l'énergie dès l'école primaire (Development of an energy chain model to help students adopt a global vision of energy as early as at the primary school level). Review of Science, Mathematics and ICT Education, 12(1), 41-60. https://doi.org/10.26220/rev.2844

Chen, B., Eisenkraft, A., Fortus, D., Krajcik, Neumann, J.K., Nordine, J., et al. (2014). Teaching and learning of energy in K-12 Education. New York: Springer. https://doi.org/10.1007/978-3-319-05017-1

Cohen. L, Manion, L., \& Morrison, K. (2007). Research Methods in Education. London: Routledge. https://doi.org/10.4324/9780203029053

Colonnese, D., Heron, P., Michelini, M., Santi, L., \& Stefanel, A. (2012). A vertical pathway for teaching and learning the energy concept. Review of Science, Mathematics and ICT Education, 6(1), 21-50. https://doi.org/10.26220/rev.1696

Dalapa, A., Vayena, B., Sissamperi, N., \& Koliopoulos, D. (2019). Using a hydraulics bench to investigate 6th grade students' energy conceptions. Educational Journal of the University of Patras UNESCO Chair, 6(1), 225-231. https://doi.org/10.26220/une.2973

Delegkos, N., \& Koliopoulos, D. (2020). Constructing the 'energy' concept and its social use by students of primary education in Greece. Research in Science Education, 50(2), 393-418.

https://doi.org/10.1007/s11165-018-9694-y

Dimopoulos, K., Koulaidis, V., \& Sklaveniti, S. (2005). Towards a framework of socio-linguistic analysis of science textbooks: The Greek case. Research in Science Education, 35(2-3), 173-195.

https://doi.org/10.1007/s11165-004-8162-z 
Domenech, L.J., Gil-Perez, D., Gras-Marti, A., Guisasola, J., Martinez-Torregrosa, J., Salivas, J., et al. (2007). Teaching of energy issues: A debate proposal for a global reorientation. Science \& Education, 16(1), 43-64. https://doi.org/10.1007/s11191-005-5036-3

Driver R., \& Millar, R. (1986). Teaching energy in schools: Towards an analysis of curriculum approaches: In Driver R. \& Millar R. (Eds.). Energy Matters. University of Leeds.

Eilam, B., \& Gilbert, J. (2014). The significance of visual representations in the teaching of science. In Eilam, B., \& Gilbert, J. (Eds.), Science teachers' use of visual representations, 3-28. New York: Springer. https://doi.org/10.1007/978-3-319-06526-7_1

Evagorou, M., Korfiati, K., Nicolaou, C., \& Constantinou, C. (2009). An Investigation of the Potential of Interactive Simulations for Developing System Thinking Skills in Elementary School: A case study with fifth graders and sixth graders. International Journal of Science Education, 31(5), 655-674. https://doi.org/10.1080/09500690701749313

Fensham, P., Gunstone, R., \& White, R. (1994). The content of science. A constructivist approach to its teaching and learning. London: The Falmer Press.

Frank, M. (2000). Engineering Systems Thinking and Systems Thinking. Systems Engineering, 3(3), 163-168. https://doi.org/10.1002/1520-6858(200033)3:3<163::AID-SYS5>3.0.CO;2-T

Harlen, W. (2013). Inquiry-based learning in science and mathematics. Review of Science, Mathematics and ICT Education, 7(2) 9-33. https://doi.org/10.26220/rev.2042

Harrison, A., \& Treagust, D, (2000). A typology of school science models. International Journal of Science Education, 22(9), 1011-1026. https:// doi.org/10.1080/095006900416884

Hmelo-Silver, C., \& Azevedo, R. (2006). Understanding complex systems: Some core challenges. The Journal of the Learning Sciences, 15(1), 53-61. https://doi.org/10.1207/s15327809j1s1501_7

Jacobson, M., \& Wilensky, U. (2006). Complex systems in education: Scientific and educational importance and implications for the learning Sciences. The Journal of the Learning Sciences, 15(1), 11-34.

https://doi.org/10.1207/s15327809j1s1501_4

Jewett, W.J. (2008). Energy and the Confused Student II: Systems. The Physics Teacher, 46(2), 81-86. https://doi.org/10.1119/1.2834527

Johnson, B., \& Cincera, J. (2019). Development of the ecological concepts of energy flow and materials cycling in middle school students participating in earth education programs. Studies in Educational Evaluation, 63, 94-101. https://doi.org/10.1016/j.stueduc.2019.08.003

Koliopoulos, D. (2014). Energy in education, Ion (in Greek).

Koliopoulos, D. (2013). Is it possible to teach energy in preschool education? Proceedings of the WCPE Conference, 451-455.

Koliopoulos, D., \& Ravanis, K. (2001). Didactic implications from students' ideas about energy: an approach to mechanical, thermal and electrical phenomena. Themes in Education, 2(2-3), 161-173.

Koliopoulos, D., Aduriz-Bravo, A., \& Ravanis, K. (2012). El «análisis del contenido conceptual» de los currículos y programas de ciencias: una posible herramienta de mediación entre la didáctica y la enseñanza de las ciencias (The «analysis of conceptual contents» of science curricula and programmes: A possible mediation tool between Science Education research and practice). Enseñanza de las Ciencias, 29(3), 315-324. https://doi.org/10.5565/rev/ec/v29n3.562

Koliopoulos, D., \& Constantinou, C. (2012). Energy in Education. Review of Science, Mathematics and ICT Education, 6(1), 3-6. https://doi.org/10.26220/rev.1697

Kubsch, M., Nordine, J., Fortus, D., Krajcik, J., \& Neumann, K. (2019). Supporting students in using energy ideas to interpret phenomena: The role of an energy representation. International Journal of Science and Mathematics Education. https://doi.org/10.1007/s 10763-019-10035-y

Lacy, S., Tobin, R., Wiser, M., \& Crissman, S. (2014). Looking through the energy lens: A proposed learning progression for energy in grades 3-5. In Chen, B., Eisenkraft, A., Fortus, D., Krajcik, J., 
Neumann, K., Nordine, J., \& Scheff, A. (Eds.), Teaching and learning of energy in K- 12 Education, 241-265. New York: Springer. https://doi.org/10.1007/978-3-319-05017-1_14

Leach, J., \& Scott, P. (2003). Individual and sociocultural views of learning in science education. Science \& Education, 12(1), 91-113. https://doi.org/10.1023/A:1022665519862

Lemeignan, G., \& Weil-Barais, A. (1994). A developmental approach to cognitive change in mechanics. International Journal of Science Education, 16(1), 99-120. https://doi.org/10.1080/0950069940160107

Lijnse, P. (1990). Energy between the lifeworld of pupils and the world of physics. Science Education, 74(5), 571-583. https://doi.org/10.1002/sce.3730740507

Lijnse, P. (1995). "Developmental research" as a way to an empirically based "didactical structure" of science. Science Education, 79(2), 189-199. https://doi.org/10.1002/sce.3730790205

Lindsay, B., Heron, P., \& Shaffer, P. (2012). Student understanding of energy: Difficulties related to systems. American Journal of Physics, 80(2), 154-163. https://doi.org/10.1119/1.3660661

Lippard, C., Lamm, M., Tank, K., \& Choi, J. (2019). Pre-engineering thinking and the engineering habits of mind in preschool classroom. Early Childhood Education Journal, 47(2), 187-198.

https://doi.org/10.1007/s10643-018-0898-6

Malandrakis, G. (2007). Children's ideas about commercial electricity generation. School Science Review, 327, 45-51.

Meli, K., \& Koliopoulos, D. (2019). Model-based simulation design for the students' conceptual understanding of introductory thermodynamics. Journal of Physics: Conf. Ser, 1287.

https://doi.org/10.1088/1742-6596/1287/1/012054

Millar, R. (2005). Teaching about energy. Research Paper 2005/11. York, Department of Educational Studies, University of York.

Minner, D., Levy, J.A., \& Century, J. (2010). Inquiry-Based Science Instruction -What Is It and Does It Matter? Results from a Research Synthesis Years 1984 to 2002. Journal of Research in Science Teaching, 47(4), 474-496. https://doi.org/10.1002/tea.20347

Papadouris, N., \& Constantinou, C.P. (2016). Investigating middle school students' ability to develop energy as a framework for analyzing simple physical phenomena. Journal of Research in Science Teaching, 53(1), 119-145. https://doi.org/10.1002/tea.21248

Qualter, A. (1995). A source of power: Young children's understanding of where electricity comes from. Research in Science \& Technological Education, 13(2), 177-186. https://doi.org/10.1080/0263514950130207

Ruthven, K., Laborde, C., Leach, J., \& Tiberghien, A. (2009). Design tools in didactical research: Instrumenting the epistemological and cognitive aspects of the design of teaching sequences. Educational Researcher, 38(5), 329-342. https://doi.org/10.3102/0013189X09338513

Sissamperi, N., \& Koliopoulos, D. (2015). A didactical approach of large-scale electricity generation systems at the elementary school level. Educational Journal of the University of Patras UNESCO Chair, 2(2), 14-24. https://doi.org/10.26220/une.2234

Scherr, R., Harrer, B., Close, H., Daane, A., DeWater, L., Robertson, A., et al. (2016). Energy Tracking Diagrams. The Physics Teacher, 54(2), 96-102. https://doi.org/10.1119/1.4940173

Skamp, K., Boyes, E., Stanisstreet, M., Rodriguez, M, Malandrakis, G., Forther, R., et al. (2019). Renewable and nuclear energy: An international study of students' beliefs about, and willingness to act, in relation to two energy production scenarios. Research in Science Education, 49(2), 295-329.

https://doi.org/10.1007/s11165-017-9622-6

Solomon, J. (1985). Learning and evaluation: a study of school children's views on the social uses of energy. Social Studies of Science, 15(2), 343-371. https://doi.org/10.1177/030631285015002005

Stavropoulos, V., \& Koliopoulos, D. (2019). Teaching energy concepts in complex technological systems: The case of the car. Educational Journal of the University of Patras UNESCO Chair, 6(1), 308-314.

https://doi.org/10.26220/une.2992 
Stavropoulos, V., Lavidas, K., \& Koliopoulos, D. (2019). How 12-13 y.o. students conceive the energy concept by studying the complex technological system of the car. Science Teaching. Research and Practice, 70-71, 27-51 (In Greek).

Tala, S. (2008). Unified View of Science and Technology for Education: Technoscience and Technoscience Education. Science \& Education, 18(2-3), 275-298. https://doi.org/10.1007/s11191-008-9145-7

Tiberghien, A. (1994). Modeling as basis for analyzing teaching-learning situations. Learning and Instruction, 4(1), 71-87. https://doi.org/10.1016/0959-4752(94)90019-1

Tiberghien, A. (1996). Construction of prototypical situations in teaching the concept of energy. In Welford, G., Osborne, J., \& Scott, P. (Eds.), Research in science education in Europe. Current issues and themes 100-114. London: The Falmer Press.

Tiberghien, A. (1997). Learning and Teaching: Differentiation and Relation. Research in Science Education, 27(3), 359-382. https://doi.org/10.1007/BF02461759

Tiberghien, A. (2004). Causalité dans l'apprentissage des sciences (Causality in science learning). Intellectica, 38, 69-102. https://doi.org/10.3406/intel.2004.1709

Tiberghien, A., \& Megalakaki, O. (1995). Characterization of a modeling activity for a first qualitative approach to the concept of energy. European Journal of Psychology of Education, 10(4), 369-383. https://doi.org/10.1007/BF03172927

Tiberghien, A., Vince, J., \& Gaidioz, P. (2009). Design-based Research: Case of a teaching sequence on mechanics. International Journal of Science Education, 31(17), 2275-2314. https://doi.org/10.1080/09500690902874894

Tobin, R., Lacy, S., Crissman, S., \& Haddad, N. (2018). Model-based reasoning about energy: A fourthgrade case study. Journal of Research in Science Teaching, 55(8), 1134-1161. https://doi.org/10.1002/tea.21445

Van Huis, C., \& Van der Berg, E. (1993). Teaching energy: A systems approach. Physics Education, 28(3), 146-153. https://doi.org/10.1088/0031-9120/28/3/003

Vince, J., \& Tiberghien, A. (2012). Enseigner l'énergie en physique à partir de la question sociale du défi énergétique [Teaching energy in physics within the social question of the energy challenge]. Review of Science, Mathematics and ICT Education, 6(1), 89-124. https://doi.org/10.26220/rev.1625

Wendell, K. (2014). Opportunities for reasoning about energy within elementary school engineering experiences, In Chen, B., Eisenkraft, A., Fortus, D., Krajcik, J., Neumann, K., Nordine, J., \& Scheff, A. (Eds.), Teaching and learning of energy in K-12 Education, 267-283. New York: Springer.

Published by OmniaScience (www.omniascience.com)

Journal of Technology and Science Education, 2021 (www.jotse.org)

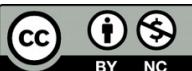

Article's contents are provided on an Attribution-Non Commercial 4.0 Creative commons International License. Readers are allowed to copy, distribute and communicate article's contents, provided the author's and JOTSE journal's names are included. It must not be used for commercial purposes. To see the complete licence contents, please visit https://creativecommons.org/licenses/by-nc/4.0/. 